\title{
O Silêncio da Pintura Ingênua nos Ateliês Psiquiátricos
}

\author{
Arley Andriolo ${ }^{1}$ \\ Universidade de São Paulo
}

\begin{abstract}
RESUMO - As pinturas produzidas nos ateliês psiquiátricos que representam paisagens, lugares e outros temas do mundo exterior, não receberam grande atenção dos pesquisadores. O problema está numa idéia acerca da criação artística na qual as referências ao mundo material e às imagens do inconsciente representam dois tipos distintos de obras de arte. Este artigo analisa esse problema por meio de uma abordagem fenomenológica, por meio da qual conclui-se a indistinção da separação entre o mundo exterior e a criação interior na produção da obra de arte. A obra de arte está enraizada entre o artista e o mundo.
\end{abstract}

Palavras-chave: psicologia da arte; arte bruta; recepção estética; percepção.

\section{The Silence of Naïve Painting in the Psychiatric Artist's Workshops}

\begin{abstract}
The paintings produced in the psychiatric artist's workshops that represent landscapes, places and other themes of the exterior world did not receive great attention from the researchers. The problem lies on an idea about the artistic creation in which the references to the material world and the unconscious images represent two distinct types of works of art. This article analyses this problem by means of a phenomenological approach through which one can conclude the undistinguished separation of the external world and the interior creation in the production of a work of art. The work of art is rooted between the artist and the world..
\end{abstract}

Key words: psychology of art; raw art; esthetic reception; perception.

Averiguando a coleção de pinturas e desenhos do acervo do Museu Osório Cesar, no Complexo Hospitalar de Juquery, salta aos olhos a grande quantidade de obras que se enquadram dentro daquilo que os estudiosos convencionaram chamar de "art naïf”, ou "arte ingênua". No entanto, elas ali estão silenciadas. Examinando os intérpretes das obras produzidas no contexto asilar, entre psiquiatras, psicólogos e críticos de arte, nada ou pouco se diz a seu respeito.

Diante dessa dupla constatação, este texto pretende apontar o porquê desse silêncio. Basicamente, por meio de uma revisão dos discursos produzidos acerca da produção artística daquele hospital, pode-se identificar a presença de um pressuposto teórico da Psicologia da Arte que distinguia duas categorias de obras de arte: uma considerava as representações de imagens exteriores ao criador, por isso, pouco interessantes ao exame psicológico; outra reconhecia as imagens provenientes do interior, por conseguinte, sugerindo o objeto privilegiado da Psicologia.

\section{A "pintura ingênua" nos asilos}

Pelo menos desde a década de 1930 as produções plásticas do Hospital de Juquery foram expostas fora dos muros da instituição. Em todas as mostras, dois conjuntos de obras apresentavam-se bem distintos. Um grupo era formado por pinturas densas, carregadas de tintas em pinceladas fortes, repletas de imagens oníricas, desenhos sobrepostos e escrituras enigmáticas. Outro vertia cenas bucólicas,

1 Endereço: Laboratório de Estudos em Psicologia da Arte, Departamento de Psicologia Social e do Trabalho, IP-USP, Av. Prof. Mello Moraes, 1721, Bloco A, Cidade Universitária, São Paulo, SP, Brasil 05508-900. E-mail: arley@usp.br campestres, revelando particularidades da vida rural brasileira, festas populares, vilarejos, animais, etc. Essas duas variedades foram reconhecidas pela crítica de arte e pelos psicólogos como referentes a dois campos de saberes distintos. O primeiro configurava-se como objeto privilegiado, de psiquiatras e psicólogos, enquanto o segundo entrava para o campo propriamente artístico de obras nomeadas "ingênuas".

Com base no termo oitocentista nä̈veté, fixado sobretudo pelo escritor realista francês Champfleury, a noção de ingenuidade em arte passou a designar um esquema técnico notável na produção plástica de pessoas pobres e sem educação formal. Qual seja: a pintura de cavalete, realizada em cores primárias sobre tela, representando cenas de vida campestre, com festas populares, casarios, fazendas, entre outros temas provincianos. Não será necessário demonstrar aqui os problemas pertinentes ao campo da "arte ingênua". Para a compreensão da questão, basta considerar a acepção romântica do termo, por exemplo, observável na síntese escrita por Pedro Manuel (1979, p. 821), intitulada "Os primitivos", no livro Arte no Brasil. Ali, lê-se a seguinte epígrafe: "Nas criações plásticas espontâneas, a visão otimista e ingênua de um mundo ideal, pleno de felicidade".

Desse modo, a delimitação temática e técnica da "arte primitiva" - nesse contexto equivalente de "arte ingênua" - ocultava os conflitos de classe social manifestos na produção plástica popular. Em primeiro lugar, devido a sua recepção a partir do olhar romântico do conhecedor de arte, delimitavam-se as obras por uma determinada representação de um Brasil imaginário, sem tensões e lutas sociais. Em segundo lugar, nos anos 1970, o campo da "arte ingênua" abria-se à participação de outros interessados que não apenas o restrito círculo de artistas populares dedicados à pintura (Andriolo, 2004). Falas do tipo "colorismo primitivo" e "ingenuidade" subordinavam o problema de 


\section{A. Andriolo}

classes, produzindo a ilusão de harmonia campestre do ser brasileiro, muito de acordo com a visão européia de nossa arte, ao que se pode deduzir do sucesso de nossos "primitivos" noutros países.

Pode-se afirmar, portanto, que embora os pintores provenientes dos hospícios sejam representados pelo drama evocado em suas obras - procedimento que adjudica a internação -, foram eles também criadores incessantes de um imaginário alegre e ingênuo. $\mathrm{O}$ mesmo médico que chamava a atenção para o sofrimento psíquico de Aurora, projetado em parte de suas obras, comparava as pinturas de Farid com as de Heitor dos Prazeres (Fraletti, 1954).

Farid Geber, nascido por volta de 1918, foi internado no Juquery sob o julgamento de ser "catatônico" ou "esquizofrênico". Os pareceres médicos acerca de suas pinturas não deixavam de procurar as estereotipias de sua expressão plástica (Yahn, 1951). No entanto, a rica produção iconográfica de Farid, realizada na década de 1950, passa por cenas rurais e religiosas, atingindo mesmo o detalhamento poético numa gravura onde pássaros de frente e de lado dispõem-se sobre um telhado (s.d., gravura em linóleo sobre papel, 32,4 x 40,4 cm, col. MOC) ${ }^{2}$. A temática dos pássaros aparece de maneira genial num desenho (s.d., grafite e lápis de cor sobre papel, 0,34 x 0,415 cm, col. MOC), no qual está riscada uma árvore sobre um fundo vermelho a ocupar exatamente o centro da composição, sobre ela pousam vários pássaros, todos iguais na cor amarela e peito vermelho. Noutra obra, uma representação típica dos "ingênuos" (4 fev. 1954, lápis de cor e grafite sobre papel, 0,37 x 0,41 cm, col. MOC), uma festa popular nos revela dois grupos de personagens, um vestido de azul e verde e outro de vermelho, preparados para tocar seus instrumentos.

O marcante bucolismo dessa produção fez ilustração de um suplemento do Correio Paulistano (19 fev. 1956, pp. 45), quando apresentou quatro imagens de Farid Geber e uma de Shara Campos, também ela interna do Juquery, dedicada a retratar jardins, flores e árvores. As expressões plásticas que podem ser enquadradas nessa visão "ingênua" não são uma exceção em meio ao conjunto de obras remanescentes dos ateliês psiquiátricos. Baseando-se na coleção do Hospital de Juquery, pode-se encontrar nomes como Braz Navas (1919-1968), Sabado Quinterni (c. 1923-?), Francisca Baron (c. 1925-?), Ioitiro Akaba (?-1968), Masayo Seta (1927-1990) e Toski Todo (1920-1971).

Navas realizou, entre outras, uma série de pequenos desenhos cujo tema condutor é a natureza, sejam árvores alinhadas no primeiro plano, em meio às quais aparecem animais, cavalos, bois, às vezes um galo, ou casas, choupanas e igrejinhas. Mostra seu domínio na distribuição dos elementos pelo plano por meio de riscos rápidos formando a vegetação esparsa, um carro e uma carroça, uma igreja e outras edificações (Sem título, década de 1950, lápis de cera e grafite sobre papel, 15 x $12 \mathrm{~cm}$, col. MOC). Sabado, por sua vez, embora mais esquemático em seus traços, retrata a imagem da paisagem em cores primárias, como num desenho em que um homem de chapéu toca sua flauta diante de uma casa cercada de grama e árvores (Sem título, 27 jan. 1950, guache sobre cartão, 57 x 49 cm, col. CEE). Por sua vez, Francisca Baron Ribeiro, com suas cores vivas, pintou uma paisagem lacustre onde um pescador e sua rede estão acompanhados por duas garças, deixando ao fundo as casi-

2 As siglas das coleções citadas referem-se aos seguintes acervos: CEE - Centre d'Étude de l'Expression, Centre Hospitalier Sainte-Anne, Paris, Fr.; MAC-USP - Museu de Arte Contemporânea da Universidade de São Paulo, SP, Br.; MOC - Museu Osório Cesar, Complexo Hospitalar do Juquery, Franco da Rocha, SP, Br. nhas, a mata e as montanhas (Sem título, c. 1949, guache sobre cartão, 50 x $62 \mathrm{~cm}$, col. CEE).

Entre os imigrantes japoneses conduzidos ao Juquery, encontram-se pintores de paisagens e cenas cotidianas que relembram sua terra natal, dando-lhes um colorido forte e onírico. Dentre eles, Ioitiro Akaba assinou uma vasta coleção de obras que remontam a 1934, na qual estão cenas de porto altamente detalhadas, com barcos, casas, pesca, pessoas, algumas vezes o porto, que parece ser composto aos moldes de uma construção oriental, personagens portando sombrinhas e belas vestimentas, além de flores em vasos (entre elas, Sem título, s.d., guache sobre papel, 33,5 x $48,4 \mathrm{~cm}$, col. MOC). O tema portuário nele, longe de ser uma representação estática e estereotipada, é extremamente variado, tem suas construções à margem, ou nos barcos e personagens; há aqueles que são evidentemente brasileiros. Masayo Seta também inscreve pessoas trajando quimonos em seus desenhos, delimitando as áreas de cor, em vermelho, amarelo e azul, por formas geométricas da arquitetura (Sem título, s.d., aquarela sobre papel, 32,3 x 47,2 cm, col. MOC). A imigrante Toski Todo completa essa breve descrição com suas cenas do cotidiano japonês, paisagens sintéticas, bem como casas, montanhas e árvores, nas quais a fluidez da pintura torna o campo mais imaginário, mais fabuloso, como se vê em sua paisagem onde nuvens vermelhas e pretas avançam por trás da graciosa luminária, para estender-se além da montanha e das casas (Sem título, s.d., aquarela e guache sobre papel, 35 x 46,5 cm, col. MOC).

Parece óbvia essa enumeração da pintura simples e bucólica produzida no hospício, desenvolvendo uma linguagem que refaz as imagens dos "primitivos" ou "ingênuos" pintores populares. No entanto, a recepção dessas obras como representantes do campo da "arte ingênua" interditava-lhes a leitura psicológica. O relativo silêncio conferido a essas pinturas evidencia um problema nuclear da Psicologia da Arte, sobretudo quando voltada aos habitantes do asilo.

\section{Uma conexão para o silêncio}

Uma conexão importante entre a recepção e o silêncio dessas pinturas pode ser localizada no início do século XX. Particularmente, esse problema é notável na interpretação divulgada originalmente por Osório Thaumaturgo Cesar, médico psiquiatra, atuante no Hospital de Juquery desde a segunda década daquele século, autor de um conhecido artigo intitulado "A arte primitiva nos alienados", em 1925. Pouco tempo depois, em 1929, lançou sua principal obra dedicada às produções plásticas no hospital: A expressão artística nos alienados (contribuição ao estudo dos symbolos na arte).

Entre as proposições contidas nesse livro, está um modelo classificatório que foi referido ao lado do esquema de Prinzhorn na breve história das idéias de arte e loucura escrita por Robert Volmat (1955). Tal método dividia as obras em quatro grupos, conforme resumiu Andriolo (2003): 1) arte do primitivo (desenho e música); 2) arte primitiva ou arcaica (desenho, escultura, decoração, poesia, música, dança); 3) arte clássica ou acadêmica (desenho, pintura, escultura, decoração, poesia, música, dança); 4) arte de vanguarda (desenho, pintura, escultura, decoração, poesia, música, dança).

Para o encaminhamento deste texto, é suficiente dizer que as produções agrupadas sob a designação de "acadêmicas" ou "clássicas" eram reconhecidas devido a sua "objetividade" e referência ao mundo exterior. São pinturas consideradas pouco simbólicas que, por isso, não interessaram ao médico do Juquery. Nas palavras de Osório Cesar (1929, p. 24): 
[muitas vezes], a arte dos alienados é uma arte normal, bem equilibrada e por isto mesmo sem grande interesse para o nosso estudo a não ser no tocante a um ou outro ponto de concepção original que ela possa ter. Por isso, comparamos as manifestações artísticas dos alienados que pertencem a esse grupo, com a arte comum, à arte acadêmica.

Ao reduzir todas as pinturas que representavam de alguma forma o mundo exterior à "arte acadêmica", o Dr. Cesar interditava a leitura psicológica dessas imagens por julgar que ali não se manifestavam as componentes subjetivas. Por outro lado, interessava-se pela arte moderna porque, segundo ele, aproxima-se das obras "primitivas" - neste caso relativo a aborígines - e dos "loucos". Diferentemente da "arte ingênua", das pinturas de paisagem, de naturezas mortas, ou outros objetos reconhecidos no mundo exterior, a arte moderna tornava visíveis os símbolos necessários para a decifração da subjetividade do criador.

A afirmação do Dr. Cesar permite compreender porque aquelas obras consideradas "ingênuas" eram, ao mesmo tempo, expostas e silenciadas. A noção que opõe subjetividade e objetividade em correlação à representação das imagens mentais e do mundo exterior desconsidera os processos próprios da produção plástica. Esta é uma questão fundamental a ser enfrentada pelos psicólogos dedicados às artes visuais. Ao reduzir a questão a um jogo de projeções, esquece-se tanto do que há de mundo no trabalho do artista quanto do que há de matéria na própria obra de arte. A seguir, apresentarei o problema da oposição entre interior e exterior na produção artística, do qual desdobra-se o problema da oposição entre alegria e sofrimento na obra de arte, para concluir que o silêncio da "pintura ingênua" decorrente dessas falsas oposições deve-se basicamente à desconsideração da própria obra de arte.

\section{O problema da oposição entre interior e exterior na produção artística}

A abordagem estética orientada pela fenomenologia fornece uma contribuição decisiva. Particularmente, Merleau-Ponty não deixa de apontar o equívoco do psicologismo que supõe uma projeção direta dos conteúdos inconscientes nas imagens artísticas. Para esse filósofo, o trabalho artístico não é somente metamorfose do imaginário, "mas também resposta ao que o mundo, o passado, as obras feitas pediam, cumprimento, fraternidade" (Merleau-Ponty, 1952/1989, p. 104). Em seu Conversas de 1948, o filósofo lembra que a arte e o pensamento modernos são difíceis não porque se baseiam unicamente em conteúdos subjetivos, mas porque "invertem o senso comum". Os objetos não se insinuam ao olhar como objetos bem conhecidos, mas "detêm o olhar, colocam-lhe questões, comunicamlhe estranhamente sua substância secreta, o próprio modo de sua materialidade e, por assim dizer, 'sangram' diante de nós" (Merleau-Ponty, 1948/2004, p. 55).

Quatro anos depois, em "A linguagem indireta e as vozes do silêncio", Merleau-Ponty insiste na inadequação da distinção entre a pintura clássica e a pintura moderna guiada pela maior ou menor ancoragem no mundo. Não se pode definir a primeira pela representação da natureza e a segunda pela referência ao subjetivo. "Não se trata de escolher entre o mundo e a arte, entre os 'sentidos' e a pintura absoluta: [ambos] imbricam-se mutuamente" (Merleau-Ponty, 1952/1989, p. 96).

A experiência perceptiva, anterior à atividade artística, projeta o artista por meio de seu corpo numa experiência essencial do mundo. Nos cursos ministrados na Sorbonne, Merleau-Ponty apóia sua reflexão no historiador da arte Erwin Panofsky - notadamente no livro A perspectiva como forma simbólica de 1924 - para demarcar a historicidade da experiência perceptiva em relação à experiência do mundo. Dizia, então:

Um quadro é o traço manifesto de uma certa relação cultural com o mundo (...) aquele que o percebe, percebe ao mesmo tempo um certo tipo de civilização. Nos casos em que a arte procurou fazer-se o menos subjetiva possivel, essa arte é a expressão de uma certa maneira de ser do homem (MerleauPonty, 1968/1990, p. 293).

Às tensões interiores que orientam o trabalho do artista, alia-se um sentimento do mundo, um engajamento que "viesse completar seu sistema de expressão do espaço". Daí o vínculo fundamental entre a História da Arte e a Psicologia da Arte, como mostrou Frayze-Pereira (1994). Por exemplo, Gombrich (1977) concluiu que a Kunstwollen, a vontade de formar, é sobretudo uma vontade de conformar, ou seja, de realizar uma síntese plástica entre o esquema mental e a experiência do mundo.

Nesse sentido, perceber não se reduz a constituir diante de si um conjunto de objetos. Com Jean-Pierre Charcosset (1982), pode-se compreender que toda obra de arte baseiase numa certa descoberta do mundo. Mundo que não se pode mais considerar como "vitrine" (Gegenwelt) ou como "ambiente" (Unwelt), mas como Lebenswelt (no dizer de Husserl):

este mundo da vida é entendido não apenas, conforme a tradução habitual, como "mundo vivido", porque ele é para nós não apenas o mundo onde nós vivemos ou que nós vivemos, mas este mundo do qual nós vivemos... como ele vive de nós (Charcosset, 1982, p. 58).

Eis o ponto nodal da estética merleau-pontyana, tanto o conhecimento quanto a obra de arte dependem da exploração do mundo pelo corpo e da sua relação com as coisas. Conceitualmente, trata-se da "fórmula carnal" (MerleauPonty, 1964; Dufrenne, 1982; Frayze-Pereira, 1995a; Andriolo, 2005).

Ao ser considerada uma obra de arte e não apenas um documento clínico restrito à análise psicopatológica, a pintura dos habitantes do asilo revela-nos um trabalho de criação fundado na percepção e na experiência do mundo. Assim, considera-se o processo perceptivo como um encontro com significados. No mundo, notou Paul Crowther (1982), as coisas imprimem-se sobre nosso corpo como presenças sensoriais - "emblemas" -, não apenas como imagens mentais ou construção mental sobre dados. Daí resultam duas noções: 1) a percepção é criativa porque o corpo, ao articular o mundo conforme significados, remete o sujeito a sua vida passada e futura; 2) o corpo opera entre as coisas e as pessoas de modo pré-reflexivo. Conforme a Fenomenologia da percepção, a vida consciente e perceptiva é "sustentada por um 'arco intencional' que projeta em torno de nós nosso passado, nosso futuro, nosso meio humano, nossa situação física, nossa situação ideológica..." (Merleau-Ponty, 1945/1999, p. 190).

A partir daí, a pintura desperta o delírio da própria visão, o pintor pratica uma teoria mágica da visão, como escreveu Merleau-Ponty (1964, p. 26) em $O$ olho e o espírito: “o espírito sai pelos olhos para ir passear nas coisas”. Quando a percepção encontra um significado imediatamente incompreensível, mas que exige sua preservação e articu- 


\section{A. Andriolo}

lação, está-se diante de um "ponto de decolagem" da criação artística (Crowther, 1982, p. 141). Diz Merleau-Ponty (1952/1989, p. 100):

é necessário que haja ocorrido este momento fecundo em que germina à superfície de sua experiência, em que um sentido operante e latente assume os emblemas que vão liberá-lo e torná-lo maneável para o artista e ao mesmo tempo que acessível aos outros. (...) O pintor em ação desconhece a antítese do homem e do mundo.

\section{O problema da oposição entre alegria e sofrimento na produção artística}

O problema do sofrimento na criação artística abre um outro campo de reflexões que não será abordado aqui (ver p. ex. Frayze-Pereira, 1995b). Sumariamente, a questão da leitura que distingue os campos da "arte ingênua" e da "psicopatologia da arte" desdobra um outro equívoco: a oposição entre uma pintura orientada pela alegria e outra pelo sofrimento. Ao considerar um artista como "primitivo" ou "ingênuo", a crítica acompanhava a leitura psicopatológica de arte que supunha dois campos artísticos definidos pela maior ou menor aderência ao mundo. Mesmo resguardando um sentido psicológico para as produções ditas naüves, subliminarmente prolongava-se o problema de distinguir as obras que apresentavam cenas campestres, paisagens rurais, festas populares, daquelas imagens de cores densas, de cenas fantásticas e perturbadoras; o primeiro grupo associado à felicidade pueril e o segundo ao sofrimento do drama subjetivo.

As considerações feitas até aqui, acerca da criação artística com base no processo perceptivo e numa operação expressiva que não abandona jamais o mundo, demonstram a inviabilidade tanto da distinção entre mundo exterior e mundo interior quanto de uma pintura devotada à alegria e outra fundada no sofrimento. Todo artista em operação, dentro ou fora do asilo, experimenta seus momentos de felicidade e de sofrimento. Ainda que seus pincéis registrem as agruras das condições de isolamento, ou representem uma fuga idílica, sua obra plástica não deixará de reviver sua própria experiência.

Apenas a título de exemplo, não será difícil notar a fragilidade da noção de felicidade aplicada aos pintores "ingênuos". Tomando como base as quatro "fases" da trajetória de José Antônio da Silva, notadas por Sant'Anna, assim como fizera Spanudis, encontraríamos a primeira delas girando em torno de 1946 e 1948, ou seja, entre o dia de sua "descoberta" e o contato direto com o museu paulista; do contato com a crítica de arte e seu auto-reconhecimento como "primitivo". Predominavam então as telas de coloridos escuros, um torpor angustiante e sufocado: "pintando paisagens muitas vezes associadas por um contorno que vai do escuro, no plano inferior do espaço pictórico, ao acinzentado, no horizonte. As margens laterais apresentam-se, constantemente, fechadas por formas de colorido escuro ou opaco" (Sant'Anna, 1993, p. 166).

O reconhecimento de Silva pelos três intelectuais paulistas deu-se num momento em que sua obra relatava o drama de sua vida, e não em cenas idílicas definidas como naïves. Sant'Anna (1993, p. 166) é categórico ao afirmar que as pinturas de José Antônio, no início de sua carreira como artista, apresentavam desenhos de traços mais rústicos, na maioria tristes, "sufocados por soluções cromáticas pouco iluminadas, nostálgicos e quase sempre fechados em todas as extremidades, simbolizando a ausência do vislumbre de saída da situação existencial em que o autor se encontra- va". Seu Cavalo indomável, de 1949 (óleo sobre tela, 35 x $50 \mathrm{~cm}$, col. MAC-USP), composto de tons de marrom e verde-escuro, é exemplar desse momento, no qual o céu nebuloso sombreia o campo, tornando ainda mais impressionantes as árvores secas ao fundo da cena. O cavalo negro, enfurecido, destaca-se no primeiro plano, reservando o canto inferior direito para o pobre cavaleiro estirado ao chão sob as patas traseiras do animal.

Assim colocada a questão, não se poderá separar dois campos da pintura nos hospitais psiquiátricos por sua maior ou menor aderência ao mundo, bem como não se poderá distingui-los pela temática dos sentimentos evocados. Podese concluir, pois, que a instituição psiquiátrica não encerra o drama psíquico, da mesma maneira que a prática pictórica ingênua não o ausenta.

\section{Conclusão}

Para concluir, convém notar que a leitura psicológica estreita, além de desdobrar os problemas da oposição entre exterior e interior, alegria e sofrimento, desconsidera por decorrência a própria materialidade da obra de arte. Mesmo no sentido catártico, dizia Dufrenne (1982, p. 102), diferentemente do sonho, o trabalho da obra "obriga o criador a afrontar a resistência da matéria". E, no dizer de FrayzePereira (1995b, p. 103), "uma obra não é um fato nem material nem ideal, mas trabalho, entendendo-se por trabalho, a negação do dado imediato enquanto imediato e, ao mesmo tempo, construção de um novo objeto". Nesse sentido, a obra de arte é dotada de uma dimensão fundamental de "reflexão" acerca da experiência do mundo, uma operação de interiorização e exteriorização que entrega ao mundo uma obra expressiva.

As pinturas de Farid Gerber, de Braz Navas, de Sabado Quinterni, de Francisca Baron, de Ioitiro Akaba, de Masayo Seta, de Toski Todo, bem como as paisagens sombrias de Aurora Cursino, todos habitantes do Juquery na década de 1950, não são apenas representações do mundo exterior, objetos e construções do asilo, como também não são projeções diretas das imagens do inconsciente. Todas elas são operações expressivas que exigem do espectador um retorno à experiência da obra, numa leitura particular que nos coloca diante da experiência do outro.

O problema da materialidade da obra nas produções de internos tem uma significação específica porque seus autores estão em grande parte desprovidos de materiais necessários à prática artística. Considere-se o fato desses artistas não possuírem outra coisa senão o seu próprio corpo (Thévoz, s.d.). O pedaço de carvão, a tinta, o papel, o barro, os retalhos de pano, o miolo de pão, ou outros materiais, tornam-se extensão do próprio corpo do artista. Corpo que é condição decisiva da percepção e da criação; corpo que não é objeto, mas que é mediação, ou seja, carne na concepção merleau-pontyana. Aqueles artistas, mesmo quando entregues às mais fantásticas imagens, refazem meticulosamente a exploração do mundo como foi exemplar a difícil trajetória do desenhista Rubens Garcia inventando imagens tão fabulosas ao mesmo tempo que concretamente enraizadas no mundo visível.

Corporalmente situado no mundo, o artista - internado ou não - realiza uma operação expressiva cuja síntese mescla definitivamente o mundo interior e o mundo exterior. O resultado dessa operação é um entre-dois materializado na obra de arte, seja qual for o tema tratado. Ao silêncio historicamente imposto à pintura "ingênua" dos ateliês psiquiátricos, a própria materialidade das obras responde de maneira eloqüente. Apresentando-se como objeto estético para novos espectadores, no longo percurso da recepção, 
é o outro que aparece diante de nós, em seus gestos, sua sensibilidade, sua experiência perceptiva, por fim, em seu mundo.

\section{Referências}

Andriolo, A. (2003). A Psicologia da arte no olhar de Osório Cesar: leituras e escritos. Psicologia Ciência e Profissão, 23(4), 74-81.

Andriolo, A. (2004). Traços primitivos: histórias do outro lado da arte no século $X X$. Tese de Doutorado, Instituto de Psicologia da Universidade de São Paulo, São Paulo.

Andriolo, A. (2005). O corpo do artista na experiência estética contemporânea. Ide, 41, 45-49.

Cesar, O. (1925). A arte primitiva nos alienados: manifestação esculptórica com caracter symbolico feiticista num caso de syndroma paranóide. Memórias do Hospital de Juquery, São Paulo, ano 2, n. 2, pp. 111-125

Cesar, O. (1929). A expressão artística nos alienados. (contribuição para o estudo dos symbolos na arte). São Paulo: Officinas Graphicas do Hospital de Juquery.

Charcosset, J.-P. (1982). La tentation du silence. Esprit, 66, 5363.

Crowther, P. (1982). Merleau-Ponty: perception into art. The British Journal of Aesthetics, 22(2), 138-149.

Dufrenne, M. (1982). Comment voir l'histoire. Esprit, 66, 4552.

Fraletti, P. (1954). Considerações sobre a arte dos alienados e dos artistas modernos. Arquivos do Departamento de Assistência a Psicopatas do Estado de São Paulo, v. XX, 3-4, 139-173.

Frayze-Pereira, J. (1994). A alteridade da arte: estética e psicologia. Psicologia USP, 5 (1-2), 35-60.

Frayze-Pereira, J. (1995a). Olho d'Água: arte e loucura em exposição. São Paulo: Escuta.

Frayze-Pereira, J. (1995b). O enigma arte-dor. Em J. FrayzePereira (Org.), Colóquio Arte-Dor (pp. 18-21). São Paulo: Instituto de Psicologia-USP/Museu de Arte Contemporânea-USP.

Gombrich, E. (1977). Art and illusion: a study in the psychology of pictorial representation (5 ed.). London: Phaidon.
Manuel, P. (Org.) (1979). Arte no Brasil. São Paulo: Abril Cultural.

Marise, L. (1956). A recuperação mental através da arte no hospital Franco da Rocha. Suplemento do Correio Paulistano, São Paulo, 19 fev., pp. 4-5.

Merleau-Ponty, M. (1964). L'oeil et l'esprit. Paris: Gallimard.

Merleau-Ponty, M. (1989). A linguagem indireta e as vozes do silêncio. Em M. Chauí (Org.), M. Merleau-Ponty, Textos selecionados (pp. 89-123). (P. S. Moraes, Trad.). São Paulo: Nova Cultural. (Trabalho original publicado em 1952)

Merleau-Ponty, M. (1990). Merleau-Ponty na Sorbonne: resumo de cursos: 1949-1952. (C. César, Trad.) Campinas: Papirus. (Trabalho original publicado em 1968)

Merleau-Ponty, M. (1999). Fenomenologia da percepção (2 ed.). (C. R. Moura, Trad.). São Paulo: Martins Fontes. (Trabalho original publicado em 1945)

Merleau-Ponty, M. (2004). Conversas - 1948. (F. Landa e E. Landa, Trad.; S. Ménasé, Org.) São Paulo: Martins Fontes. (Trabalho original publicado em 1948).

Sant'Anna, R. (1993). Silva: quadros e livros: um artista caipira. São Paulo: Editora da Universidade Estadual Paulista.

Thévoz, M. (s.d.). Il n'y a pas d'art pscyhopathologique. Em M. Thévoz, Art, folie, L.S.D., graffiti, etc (pp. 19-30). Suisse: Ed. De l'Aire.

Volmat, R. (1955). De l'évolution des idées sur "l'Art et la Folie". Histoire de la Médecine, 5(1), 29-49.

Yahn, M. (1951). Exposição de arte psicopatológica no I Congresso Internacional de Psiquiatria de Paris. Arquivos do Departamento de Assistência a Psicopatas do Estado de São Paulo, 16, 23-32.

Recebido em 25.01.2006

Primeira decisão editorial em 27.03.2006

Versão final em 20.04.2006

Aceito em 15.05.2006 